\title{
Paths to Statistical Fluency for Ecologists
}

\section{Citation}

Ellison, Aaron M. and Brian Dennis. Forthcoming. Paths to statistical fluency for ecologists.

Frontiers in Ecology and the Environment.

\section{Published Version}

http://www.esajournals.org/loi/fron

\section{Permanent link}

http://nrs.harvard.edu/urn-3:HUL.InstRepos:2766569

\section{Terms of Use}

This article was downloaded from Harvard University's DASH repository, and is made available under the terms and conditions applicable to Open Access Policy Articles, as set forth at http:// nrs.harvard.edu/urn-3:HUL.InstRepos:dash.current.terms-of-use\#OAP

\section{Share Your Story}

The Harvard community has made this article openly available.

Please share how this access benefits you. Submit a story.

Accessibility 


\section{PATHS TO STATISTICAL FLUENCY FOR ECOLOGISTS}

\author{
Aaron M. Ellison ${ }^{1,3}$ \& Brian Dennis ${ }^{2}$
}

${ }^{1}$ Harvard University, Harvard Forest, 324 North Main Street, Petersham, MA 01366

${ }^{2}$ Department of Fish \& Wildlife Resources, and Department of Statistics, University of Idaho, Moscow, ID 83844

\author{
${ }^{3}$ For all correspondence: aellison@fas.harvard.edu
}

\section{ABSTRACT}

Twenty-first century ecology requires statistical fluency. Observational and experimental studies routinely gather non-Normal, multivariate data at many spatiotemporal scales.

Experimental studies routinely include multiple blocked and nested factors. Ecological theories routinely incorporate both deterministic and stochastic processes. Ecological debates frequently revolve around choices of statistical analyses. Our journals are replete with likelihood and statespace models, Bayesian and frequentist inference, complex multivariate analyses, and papers on statistical theory and methods. We test hypotheses, model data, and forecast future environmental conditions. And many appropriate statistical methods are not automated in software packages. It is time for ecologists to understand statistical modeling well enough to construct nonstandard statistical models and apply various types of inference - estimation, hypothesis testing, model selection, and prediction - to our models and scientific questions. In short, ecologists need to move beyond basic statistical literacy and attain statistical fluency. 
In a nutshell:

24 - Ecologists need to use nonstandard statistical models and methods of statistical inference to test models of ecological processes and to address pressing environmental problems.

- Such statistical models of ecological processes include both deterministic and stochastic parts, and statistically-fluent ecologists will need to use probability theory and calculus to fit

- Many ecologists lack appropriate background in probability theory and calculus because

- A prescription for attaining statistical fluency includes: two semesters of standard calculus; a

41 Cox (Gotelli and Ellison 2004). Calculation of sums of squares was just within the reach of

42 mechanical (or human) calculators (Fig. 1), and generations of ecologists have spent many hours

43 in their labor of love: caring and curating the results of analysis of variance (ANOVA) models.

44 Basic linear models (ANOVA and regression) continue to be the dominant mode of ecological 45 data analysis; they were used in $75 \%$ of all papers published in Ecology in $2008(N=344 ; 24$ 
papers were excluded from the analysis because they were conceptual overviews, notes, or

47 commentaries that reported no statistics at all). These methods are employed most appropriately

48 to analyze relatively straightforward experiments aimed at estimating the magnitudes of a small

49 number of additive fixed effects or testing simple statistical hypotheses. Although the vast

50 majority of papers published in Ecology test statistical hypotheses (75\% reported at least one $P$ -

51 value) and estimate effect sizes (69\%), only 32\% provided assessments of uncertainty (e.g.,

52 standard errors, confidence intervals, probability distributions) on the estimates of the effect sizes

53 themselves (as distinguished from the common practice of reporting standard errors of observed

54 means).

55 But these methods do not reflect ecologists' collective statistical needs for the $21^{\text {st }}$

56 century. How can we use ANOVA and simple linear regression to forecast ecological processes

57 in a rapidly changing world (Clark et al. 2001)? Familiar examples or ecological problems that

58 would benefit from sophisticated modeling approaches include: forecasts of crop production;

59 population viability analyses; prediction of the spread of epidemics or invasive species; and

60 predictions of fractionation of isotopes through food webs and ecosystems. Such forecasts, and

61 many others like them, are integral to policy instruments such as the Millennium Ecosystem

62 Assessment (2005) or the IPCC reports (IPCC 2007). Yet such forecasts and similar types of

63 studies are uncommon in top-tier ecological journals. Why? Do ecologists limit their study

64 designs so as to produce data that will fit into classical methods of analysis? Are nonstandard

65 ecological data sometimes mis-analyzed with off-the-shelf statistical techniques (Bolker et al.

66 2009)? In the statistical shoe store, do ecologists sometimes cut the foot to fit the shoe? How do

67 we learn to do more than determine $P$-values associated with mean squared error terms in

68 analysis of variance (Butcher et al. 2007)? 
The short answer is by studying and using "models". Statistical analysis is fundamentally

70 a process of building and evaluating stochastic models, but such models were hidden or even

71 forbidden in the agricultural statistics-education tradition that emphasized practical training and

72 de-emphasized calculus. Yet, any ecological process producing variable data can (and should) be

73 described using a stochastic, statistical model (Bolker 2008). Such models may start as a

74 conceptual or "box-and-arrow" diagram, but these should then be turned into more quantitative

75 descriptions of the processes of interest. The building blocks of such quantitative descriptions are

76 deterministic formulations of the hypothesized effects of environmental variables, time, and

77 space, coupled with discrete and continuous probability distributions. These distributions, rarely

78 Normal, are chosen by the investigator to describe how the departures of data from the

79 deterministic sub-model are hypothesized to occur. The Sums of Squares - a surrogate for

80 likelihood in Normal distribution models - is no longer the only statistical currency; likelihood

81 and other such statistical objective functions are the more widely useful coins of the realm.

82 Alternatives to parametric model-based methods include non-parametric statistics and

83 machine-learning. Classical non-parametric statistics (Conover 1998) have been supplanted by

84 computer simulation and randomization tests (Manly 2006) but the statistical or causal models

85 that they test are rarely apparent to data analysts and users of packaged (especially compiled)

86 software products. Similarly, model-free machine-learning and data-mining methods (Breiman

87 2001) seek large-scale correlative patterns in data by letting the data "speak for themselves".

88 Although the adherents of these methods promise that machine-learning and data-mining will

89 make the "standard" approach to scientific understanding - hypothesis $\rightarrow$ model $\rightarrow$ test -

90 obsolete (Anderson 2008), the ability of these essentially correlative methods to advance

91 scientific understanding and provide reliable forecasts of future events has yet to be 
92 demonstrated. Thus we focus here on the complexities inherent in fitting stochastic statistical

93 models, estimating their parameters, and carrying out statistical inference on the results.

94 Our students and colleagues create or work far less frequently with stochastic statistical

95 models than they use routine ANOVA and its relatives; in 2008, only $23 \%$ of papers published in

96 Ecology used stochastic models or applied competing statistical models on their data (and about

97 half of these used automated software such as stepwise regression or MARK [White and

98 Burnham 1999] that take much of the testing out of the hands of the user to contrast among

99 models constructed from many possible combinations of parameters). Why? It may be that we

100 (or at least those of us who publish in our leading journals) primarily conduct well designed

101 experiments that test one or two factors at a time and have sufficient sample sizes and balance

102 among treatments to satisfy all the requirements of ANOVA and yield high statistical power. If

103 this is true, the complexity of stochastic models is simply unnecessary. But our data rarely are so

104 forgiving; more frequently our sample sizes are too small, our data are not Normally distributed

105 (or even continuous), our experimental and observational designs include mixtures of fixed and

106 random effects, and we know that process affect our study systems hierarchically. And finally,

107 we want to do more with our data than simply tell a good story. We want to generalize, predict,

108 and forecast. In short, we really do need to model our data.

109 We suggest that there are profound disconnections between the quantitative nature of

110 ecology, the quantitative (mathematical and statistical) skills we expect of ourselves and of our

111 students, and how we teach and learn quantitative methods. We illustrate these disconnections

112 with two motivating examples and suggest a new standard - statistical fluency - for quantitative

113 skills that are learned and taught by ecologists. We close by providing a prescription for better

114 connecting (or reconnecting) our teaching with the quantitative expectations we have for our 
115 students so that ecological science can progress more rapidly and with more relevance to society

116 at large.

Under optimal conditions, populations grow exponentially:

122 In this equation, $N_{0}$ is the initial population size, $N_{t}$ is the population size at time $t, r$ is the

123 instantaneous rate of population growth (units of individuals per infinitesimally small units of

124 time $t$ ), and $e$ is the base of the natural logarithm. This simple equation is often referred to as the

125 first law of population dynamics (Turchin 2001) and it is universally presented in undergraduate

126 ecology textbooks. Yet we all know all too well that students in our introductory ecology classes

127 view exponential growth mainly through glazed eyes. Why? Equation 1 is replete with complex

128 mathematical concepts normally encountered in the first semester of calculus: the concept of a

129 function, raising a real number to a real power, and Euler's number $e$. But the majority of

130 undergraduate ecology courses do not require calculus as a prerequisite, thereby insuring that

131 understanding fundamental concepts such as exponential growth is not an expected course

132 outcome. The current financial meltdown associated with the foreclosure of exponentially

133 ballooning sub-prime mortgages illustrates writ large Albert Bartlett's assertion that "the greatest

134 shortcoming of the human race is our inability to understand the exponential function". Surely

135 ecologists can do better.

136 Instructors of undergraduate ecology courses that do require calculus as a prerequisite

137 often find themselves apologizing to their students that ecology is a quantitative science and go 
138 on to provide conceptual or qualitative workarounds that keep course enrollments high and deans

139 happy. Students in the resource management fields - forestry, fisheries, wildlife, etc. - suffer

140 even more, as quantitative skills are further de-emphasized in these fields. Yet resource managers

141 need a deeper understanding of exponential growth (and other quantitative concepts) than do

142 academic ecologists; for example, the relationship of exponential growth to economics or its role

143 in the concept of the present value of future revenue. The result in all these cases is the

144 perpetuation of a culture of quantitative insecurity among many students.

145 The actual educational situation with our example of population growth models in

146 ecology is much worse. The exponential growth expression as understood in mathematics is the

147 solution to a differential equation. Differential equations, of course, are a core topic of calculus.

148 Indeed, because so many dynamic phenomena in all scientific disciplines are naturally modeled

149 in terms of instantaneous forces (rates), the topic of differential equations is one of the main

150 reasons for studying calculus in the first place! To avoid introducing differential equations to

151 introductory ecology classes, most ecology textbooks present exponential growth in a discrete-

152 time form: $N_{t+1}=(1+$ births - deaths $) N_{t}$ and then miraculously transmogrify this (with little or

153 no explanation) into the continuous time model given by $\mathrm{d} N / \mathrm{d} t=r N$. The attempts at intuition

154 obscure, for instance, the exact nature of the quantities "births" and "deaths" and how they

155 would be measured, not to mention the assumptions involved in discrete time versus continuous

156 time formulations.

157 Furthermore, Eqn. 1 provides no insights into how the unknown parameters ( $r$ and even

$158 N_{0}$ when population size is not known without error) ought to be estimated from ecological data.

159 To convince yourself that it is indeed difficult to estimate unknown parameters from ecological

160 data, consider the following as a first exercise for an undergraduate ecology laboratory: for a 
161 given set of demographic data (perhaps collected from headstones in a nearby cemetery),

162 estimate $r$ and $N_{0}$ in Eqn. 1 and provide a measure of confidence in the estimates.

163 Finally, to actually use Eqn. 1 to describe the exponential growth of a real population, one

164 must add stochasticity by modeling departures of observed data from the model itself. There are

165 many different ways of modeling such variability that depend on the specific stochastic forces

166 acting on the observations; each model gives a different likelihood function for the data and

167 thereby prescribes a different way for estimating the growth parameter. In addition, the choices

168 of models for the stochastic components, such as demographic variability, environmental

169 variability, and sampling variability, must be added to (and evaluated along with) the suite of

170 modeling decisions concerning the deterministic core, such as changing exponential growth to

171 some density dependent form or adding a predator. Next, extend these concepts and methods to

172 "simple" Lotka-Volterra models of competition and predation...

173

The Cumulative Distribution Function for a Normal curve

Our second motivating example deals with a core concept of statistics:

$$
\int_{a}^{b}\left(\sigma^{2} 2 \pi\right)^{-1 / 2} \exp \left[-\frac{(y-\mu)^{2}}{2 \sigma^{2}}\right] d y=\Phi(b)-\Phi(a)
$$

177 The function $\Phi(y)$ is the cumulative distribution function for the Normal distribution and Eqn. 2

178 describes the area under a Normal curve (with two parameters: mean $=\mu$ and variance $=\sigma^{2}$ )

179 between $a$ and $b$. This quantity is important because the Normal distribution is used as a model

180 assumption for many statistical methods (e.g., linear models, probit analysis), and Normal

181 probabilities can express predicted frequencies of occurrence of observed events (data). Also,

182 many test statistics also have sampling distributions that are approximately Normal. Rejection 
183 regions, $P$-values, and confidence intervals all are defined in terms of areas under a Normal 184 curve.

185 The meaning, measurement, and teaching of $P$-values continues to bedevil statisticians

186 (e.g., Berger 2003, Hubbard and Byarri 2003, Murdoch et al., 2008), yet ecologists often use and

187 interpret probability and $P$-values uncritically, and few ecologists can clearly describe a

188 confidence interval with any degree of... uh, confidence. To convince yourself that this is a real

189 problem, consider asking any graduate student in ecology (perhaps during their oral

190 comprehensive examination) to explain why $P(10.2<\mu<29.8)=0.95$ is not the correct

191 interpretation of a confidence interval on the parameter $\mu$ (original equation from Poole 1974);

192 odds are you will get an impression of someone who is not secure in their statistical

193 understanding. Bayesians should refrain for chortling about the transparency of credible sets.

194 Interpreting Bayesian credible intervals makes equally large conceptual demands (Hill 1968,

195 Lele and Dennis 2009). When pushed, students can calculate a confidence interval by hand or

196 with computer software. But interpreting it (Box 1) and generalizing its results is where the

197 difficulty lies.

198 Three centuries of study of Eqn. 2 by mathematicians and statisticians have not reduced it

199 to any simpler form, and evaluating it for any two real numbers $a$ and $b$ must be done

200 numerically. Alternatively, one can proceed through the mysterious, multi-step table-look-up

201 process, involving the $Z$-tables provided in the back of every basic statistics text. Look-up tables

202 or built-in functions in statistical software may work fine for standard probability distributions

203 such as the Normal or F distribution, but what about non-standard distributions or mixtures of

204 distributions used in many hierarchical models? Numerical integration is a standard topic in

205 calculus classes, and it can be applied to any distribution of interest, not just the area under a 
206 Normal curve. Consider the power of understanding: how areas under curves can be calculated

207 for other continuous models besides the Normal distribution; how the probabilities for other

208 distributions sometimes converge to the above form based on the Normal; and how Normal-

209 based probabilities can serve as building blocks for hierarchical models of more complex data

210 (Clark 2007). Such interpretation and generalization is at the heart of statistical fluency.

DEVELOPING STATISTICAL FLUENCY AMONG ECOLOGISTS

214 We use the term "fluency" to emphasize that a deep understanding of statistics and

215 statistical concepts differs from "literacy" (Table 1). Statistical literacy is a common goal of

216 introductory statistics courses that presuppose little or no familiarity with basic mathematical

217 concepts introduced in calculus, but it is insufficient for $21^{\text {st }}$ century ecologists. Like fluency in a

218 foreign language, statistical fluency means not only a sufficient understanding of core theoretical

219 concepts (grammar in languages, mathematical underpinnings in statistics) but also the ability to

220 apply statistical principles and adapt statistical analyses for nonstandard problems (Table 1).

221 We must recognize that calculus is the language of the general principles that underlie

222 probability and statistics. We emphasize that statistics is not mathematics; rather, like physics,

223 statistics uses a lot of mathematics (De Veaux and Velleman 2008). And ecology uses a lot of

224 statistics. But the conceptual ideas of statistics are really hard. Basic statistics contains abstract

225 notions derived from those in basic calculus, and students who take calculus courses and use

226 calculus in their statistics courses have a deeper understanding of statistical concepts and the

227 confidence to apply them in novel situations. In contrast, students who take only calculus-free, 
228 cookbook-style statistical methods courses often have a great deal of difficulty adapting the

229 statistics that they know to ecological problems for which those statistics are inappropriate.

230 For ecologists, the challenge of developing statistical fluency has moved well beyond the

231 relatively simple task of learning and understanding fundamental aspects of contemporary data

232 analysis. The very theories themselves in ecology include stochastic content that can only be

233 interpreted probabilistically and include parameters that can only be estimated using complex

234 statistics. For example, conservation biologists struggle with (and frequently mis-express) the

235 distinctions between demographic and environmental variability in population viability models

236 and must master the intricacies of first passage properties of stochastic growth models.

237 Community ecologists struggle to understand (and figure out how to test) the "neutral" model of

238 community structure (Hubbell 2001), itself related to neutral models in genetics (see Leigh 2007)

239 with which ecological geneticists must struggle. Landscape ecologists must struggle with

240 stochastic dispersal models and spatial processes. Behavioral ecologists must struggle with

241 Markov chain models of behavioral states. All must struggle with huge individual-based

242 simulations and hierarchical (random or latent effects) models. No subfield of ecology, no matter

243 how empirical the tradition, is safe from encroaching stochasticity and the attendant need for the

244 mathematics and statistics to deal with it.

Statistics is a post-calculus subject

What mathematics do we need - to create, parameterize, and use stochastic statistical

248 models of ecological processes? At a minimum, we need calculus. We must recognize that

249 statistics is a post-calculus subject and that calculus is a prerequisite for development of

250 statistical fluency. Expectation, conditional expectation, marginal and joint distributions, 
251 independence, likelihood, convergence, bias, consistency, distribution models of counts based on

252 infinite series... are key concepts of statistical modeling that must be understood by practicing

253 ecologist, and these are straightforward calculus concepts. No amount of pre-calculus statistical

254 "methods" courses can make up for this fact. Calculus-free statistical methods courses doom

255 ecologists to a lifetime of insecurity with regard to the ideas of statistics. Such courses are like

256 potato chips: virtually no nutritional value, no matter how many are consumed. Pre-calculus

257 statistics courses are similar to pre-calculus physics courses in that regard; both have reputations

258 for being notorious, unsatisfying parades of mysterious plug-in formulas. Ecologists who have

259 taken and internalized post-calculus statistics courses are ready to grapple with the increasingly

260 stochastic theories at the frontiers of ecology and will be able to rapidly incorporate future

261 statistical advances in their kit of data analysis tools. How do our students achieve statistical

262 fluency?

263

\section{The prescription}

265 Basic calculus, including an introduction to differential equations, seems to us to be a

266 minimum requirement. Our course prescription includes (1) two semesters of standard calculus

267 and an introductory, calculus-requiring introductory statistics course in college; and (2) a two-

268 semester post-calculus sequence in probability and mathematical statistics in the first or second

269 year of graduate school (Box 2). But it is not enough to simply take calculus courses, as calculus

270 already is clearly required (or at least recommended) by virtually all undergraduate science

271 degree programs (Fig. 2). Rather, calculus must be used; not only in statistics courses taken by

272 graduate students in ecology but most importantly in undergraduate and graduate courses in

273 ecology (including courses in resource management and environmental science)! If this seems 
274 overly daunting, consider that Hutchinson (1978) summarizes "the modicum of infintesimal

275 calculus required for ecological principles" in three and a half pages. Contemporary texts (such

276 as Clark 2007 or Bolker 2008) in ecological statistical modeling use little more than single

277 variable calculus and basic matrix algebra. Like Hutchinson, Bolker (2008) covers the essential

278 calculus and matrix algebra in 4 pages, each half the size of Hutchinson's! Clark's (2007) 100-

279 page mathematical refresher is somewhat more expansive, but in all cases the authors illustrate

280 that knowledge of some calculus allows one to advance rapidly on the road to statistical fluency.

281 We emphasize that nascent ecologists need not take more courses to attain statistical

282 fluency; they just need to take courses that are different from standard "methods" classes.

283 Current graduate students may need to take refresher courses in calculus and mathematical

284 statistics, but we expect that our prescription (Box 2) will actually reduce the time that future

285 ecology students spend in mathematics and statistics classrooms. Most undergraduate life science

286 students already take calculus and introductory statistics (Fig. 2). The pre-calculus statistical

287 methods courses that are currently required can be swapped out in favor of two semesters of

288 post-calculus probability and statistics. Skills in particular statistical methods can be obtained

289 through self-study or through additional methods courses; a strong background in probability and

290 statistical theory makes self-study a realistic option for rapid learning for motivated students.

Why not just collaborate with professional statisticians?

293 In the course of speaking about statistics education to audiences of ecologists and natural

294 resource scientists, we often are asked questions such as: "I don't have to be a mechanic to drive

295 a car, so why do I need to understand statistical theory to be an ecologist? (and why do I have to

296 know calculus to do statistics?)" Our answer, the point of this article, is that the analogy of 
297 statistics as a tool or black box increasingly is failing the needs of ecology. Statistics is an

298 essential part of the thinking, the hypotheses, and the very theories of ecology. Ecologists of the

299 future should be prepared to confidently use statistics so that they can make substantial progress

300 at the frontiers of our science.

$301 \quad$ "But," continues the questioner, "why can't I just enlist the help of a statistician?"

302 Collaborations with statisticians can produce excellent results and should be encouraged

303 wherever and whenever possible, but ecologists will find that their conversations and interactions

304 with professional statisticians will be enhanced if ecologists have done substantial statistical

305 ground work before their conversation begins and if both ecologists and statisticians speak a

306 common language (mathematics!). Collaborations between ecologists and statisticians also can

307 be facilitated by building support for consulting statisticians into grant proposals; academic

308 statisticians rely on grant support as much as academic ecologists do. However, ecologists cannot

309 count on the availability of statistical help whenever it is needed. And, statistical help may be

310 unavailable at many universities. Thus, we believe that ecologists should be self-sufficient and

311 self-assured. We should master our own scientific theories and be able to discuss with confidence

312 how our conclusions are drawn from ecological data. We should be knowledgeable enough to

313 recognize what we do understand and what we do not, learn new methods ourselves, and seek

314 out experts who can help us increase our understanding.

318 all ages through stories and narratives (Fig. 3; see also Molles 2006). We do not disagree with the

319 importance of telling a good story and engaging our students with detailed narratives of how the 
320 world works. Nor do we minimize the importance of doing "hands-on" ecology through inquiry-

321 based learning, which is both important and fun. Field trips, field work, and lab work are exciting

322 and entertaining, draw students into ecology, and dramatically enhance ecological literacy. For

323 individuals who pursue careers in fields outside of science, qualitative experiences and an

324 intuitive grasp of the story-line can be sufficient (Cope 2006). But for our students who want the

325 deepest appreciation and joy of how science works - understanding how we know what we know

326 - and for those of us who are in scientific careers and are educating the next generation of

327 scientists, we should use the richest possible language for our narratives of science. And that

328 language is mathematics.

\section{ACKNOWLEDGEMENTS}

331 This paper is derived from a talk on statistical literacy for ecologists presented by the 332 authors at the 2008 ESA Annual Meeting in the symposium "Why is ecology hard to learn?" We

333 thank Charlene D'Avanzo for organizing the symposium and inviting our participation, the other

334 participants and members of the audience for their thoughtful and provocative comments that

335 helped us to refine our arguments, and Ben Bolker, an anonymous reviewer, and the Associate

336 Editor for useful comments that improved the final version.

REFERENCES

339 Anderson C. 2008. The Petabyte age: because more isn't just more - more is different. Wired

$340 \quad$ Magazine Issue 16.07 (July 2008):106-120.

341 Armsworth PR, Gaston KJ, Hanley ND, et al. 2009. Contrasting approaches to statistical

342 regression in ecology and economics. J Appl Ecol 46: 265-268. 
343 Berger JO. 2003. Could Fisher, Jeffreys and Neyman have agreed on testing (with comments and rejoinder). Stat Sci 18:1-32.

Bolker B. 2008. Ecological models and data in R. Princeton, NJ: Princeton University Press.

346 Bolker B, Brooks ME, Clark CJ, et al. 2009. Generalized linear mixed models: a practical guide for ecology and evolution. Trends Ecol. Evol 24:127-135.

348 Breiman L. 2001. Statistical modeling: the two cultures (with discussion). Stat. Sci 16:199-231.

349 Butcher JA, Groce JE, Lituma CM, et al. 2007. Persistent controversy in statistical approaches in wildlife sciences: a perspective of students. $J$ Wildlife Manage 71:2142-2144.

Clark JS. 2007. Models for ecological data: an introduction. Princeton, NJ: Princeton University

Clark JS, Carpenter SR, Barber M, et al. 2001. Ecological forecasts: an emerging imperative. Science 293:657-660.

Conover WJ. 1998. Practical nonparametric statistics, $3^{\text {rd }}$ ed. New York: John Wiley and Sons.

356 Cope L. 2006. Understanding and using statistics. In: Blum D, Knudson M, and Henig RM (Eds). A field guide for science writers: the official guide of the National Association of

delMas RC. 2002. Statistical literacy, reasoning, and learning: a commentary. J Stat Ed 10.

360 De Veaux RD, and Velleman PF. 2008. Math is music; statistics is literature (or, why are there no six-year-old novelists?). AmStat News September 2008:54-58.

362 Desai A, Moorcroft PR, Bolstad PV and Davis KJ. 2007. Regional carbon fluxes from an 363 observationally constrained dynamic ecosystem model: impacts of disturbance, $\mathrm{CO}_{2}$ fertilization, and heterogeneous land cover. J. Geophys Res 112: G01017 
365 Devore JL. 2007. Probability and statistics for engineering and the sciences, $7^{\text {th }}$ ed. Belmont, CA:

366 Duxbury Press.

367 Gotelli NJ, and Ellison AM. 2004. A primer of ecological statistics. Sunderland, MA: Sinauer

$368 \quad$ Associates.

369 Hill BM. 1968. Posterior distribution of percentiles: Bayes' theorem for sampling from a

$370 \quad$ population. J Am Stat Assoc 63:677-691.

371 Hubbard R, and Byarri MJ. 2003. Confusion over measures of evidence ( $p$ 's) versus errors ( $\alpha$ 's)

372 in classical statistical testing (with discussion and rejoinder). Am Stat 57:171-182.

373 Hubbell SP. 2001. The unified neutral theory of biodiversity and biogeography. Princeton, NJ:

$374 \quad$ University Press.

375 Hutchinson G.E. 1978. An introduction to population ecology. New Haven, CT: Yale University $376 \quad$ Press.

377 IPCC. 2007. Climate Change 2007: Synthesis report. Contribution of working groups I, II, and

378 III to the fourth assessment report of the intergovernmental panel on climate change.

379 Geneva: IPCC.

380 Larson RJ, and Marx ML. 2005. An introduction to mathematical statistics and its applications, $381 \quad 4^{\text {th }}$ ed. Upper Saddle River, NJ: Prentice-Hall.

382 Leigh, EG Jr. 2007. Neutral theory: a historical perspective. J Evol Biol 20:2075-2091.

383 Lele SR, and Dennis B. 2009. Bayesian methods for hierarchical models: are ecologists making a $384 \quad$ Faustian bargain? Ecol Appl 19:581-584.

385 Manly BJF. 2006. Randomization, bootstrap and Monte Carlo methods in biology, $3^{\text {rd }}$ ed. Boca 386 Raton, FL: CRC Press. 
387 Matross DM et al. 2006. Estimating regional carbon exchange in New England and Quebec by

388 combining atmospheric, ground-based and satellite data. Tellus 58B: 344-358.

389 Millennium Ecosystem Assessment. 2005. Ecosystems and human well-being: synthesis.

$390 \quad$ Washington, DC: Island Press.

391 Molles M. C. 2006. Ecology: concepts and applications, $4^{\text {th }}$ edition. New York: McGraw-Hill.

392 Murdoch DJ., Tsai Y-L, and Adcock J. 2008. $p$-values are random variables. Am Stat 62:242$393 \quad 245$.

394 National Science Foundation. 1996. Undergraduate origins of recent (1991-95) science and 395 engineering doctorate recipients, detailed statistical tables, NSF 96-334. Arlington, $396 \quad$ Virginia: National Science Foundation

397 Poole RW. 1974. An introduction to quantitative ecology. New York: McGraw-Hill.

398 Rice JA. 2006. Mathematical statistics and data analysis, $3^{\text {rd }}$ edition. Belmont, CA: Duxbury $399 \quad$ Press.

400 Stoll EL. 1983. Mark I. In: Ralston A and Reilly ED (Eds.) Encyclopedia of computer science and engineering, $2^{\text {nd }}$ ed. New York: Van Nostrand Reinhold.

402 Turchin P. 2001. Does population ecology have general laws? Oikos 94:17-26.

403 Wackerly D, Mendenhall W, and Scheaffer RL. 2007. Mathematical statistics with applications, $404 \quad 7^{\text {th }}$ edition. Belmont, CA: Duxbury Press.

405 White GC and Burnham KP. 1999. Program MARK: Survival estimation from populations of 406 marked animals. Bird Study 46 (Supp.): 120-138. 
Table 1. The different components and stages of statistical literacy.* "Process" refers to a statistical concept (such as a $P$-value or confidence interval) or method.

\begin{tabular}{ccc}
\hline Basic literacy & Ability to reason statistically & Fluency in statistical thinking \\
\hline Identify the process & Explain the process & Apply the process to new situations \\
Describe it & Why does it work? & Critique it \\
Rephrase it & How does it work? & Evaluate it \\
Translate it & Generalize from it \\
Interpret it & \\
\hline
\end{tabular}


$410 \quad$ Figure Legends

411 Figure 1 - Milestones in statistical computing. A. Women (ca. 1920) in the Computing Division

412 of the U.S. Department of the Treasury (or the Veterans'Bureau) determining the bonuses to be

413 distributed to veterans of World War I. Photograph from the Library of Congress Lot 12356-2,

414 negative LC-USZ62-101229. B. Professor (and Commander) Howard Aiken, Lieutenant (and

415 later Rear Admiral) Grace Hopper, and Ensign Campbell in front of a portion of the Mark I

416 Computer. The Mark I was designed by Aiken, built by IBM, fit in a steel frame $16 \mathrm{~m}$ long $\times 2.5$

$417 \mathrm{~m}$ high, weighed approximately $4,500 \mathrm{~kg}$, and included $800 \mathrm{~km}$ of wire, It was used to solve

418 integrals required by the U.S. Navy Bureau of Ships during World War II, and physics problems

419 associated with magnetic fields, radar, and the implosion of early atomic weapons. Grace

420 Hopper was the lead programmer of the Mark I. Her experience developing its programs led her

421 to develop the first compiler for a computer programming language (which subsequently evolved

422 into $C O B O L)$, and she developed early standards for both the FORTRAN and COBOL

423 programming languages. The Mark I was programmed using punched paper tape and was the

424 first automatic digital computer in the U.S. Its calculating units were mechanically synchronized

425 by an $\sim 15-m$ long drive shaft connected to a $4 \mathrm{~kW}$ (5 horsepower) electric motor. The Mark I is

426 considered to be the first universal calculator (Stoll 1983). Photograph from the Harvard

427 University Office of News and Public Affairs, Harvard University Archives call number HUPSF

428 Computers (2), and reproduced with permission of the Harvard University Archives. C. A ca.

4292007 screen-shot of the open-source R statistical package running on a personal computer. The

430 small, notebook computers that on which we run $\mathrm{R}$ and other statistical software every day have

431 central processors that execute10,000 - 100,000 MIPS (million instructions per second). In

432 contrast, the earliest commercial computers executed 0.06-1.0 KIPS (thousand instructions per 
433 second), and Harvard's Mark I computer took approximately 6 seconds to simply multiply two

434 numbers together; computing a single logarithm took more than a minute. (Image from

435 http://www.r-project.org, copyright the R Foundation, and used with permission).

436

437 Figure 2 - Total number of quantitative courses, calculus courses, and statistics courses required 438 at the 25 liberal-arts colleges and universities that produce the majority of students who go on to 439 receive Ph.D.s in the life sciences. Institutions surveyed are based on data from the National

440 Science Foundation (1996). Data collected from department web sites and college or university

441 course catalogs, July 2008.

442

443 Figure 3 - Telling a compelling ecological story requires quantitative data. Here, Harvard

444 Forest researcher Julian Hadley describes monthly cycles of carbon storage in hemlock and

445 hardwood stands. The data are collected at 10-20 Hz from three eddy-covariance towers,

446 analyzed and summarized with time-series modeling, and incorporated into regional estimates

447 (e.g., Matross et al. 2006) and forecasts (e.g., Desai et al. 2007), and used to determine regional

448 and national carbon emissions targets and policies. Photograph by David Foster, and used with

449 permission of the Harvard Forest Archives. 


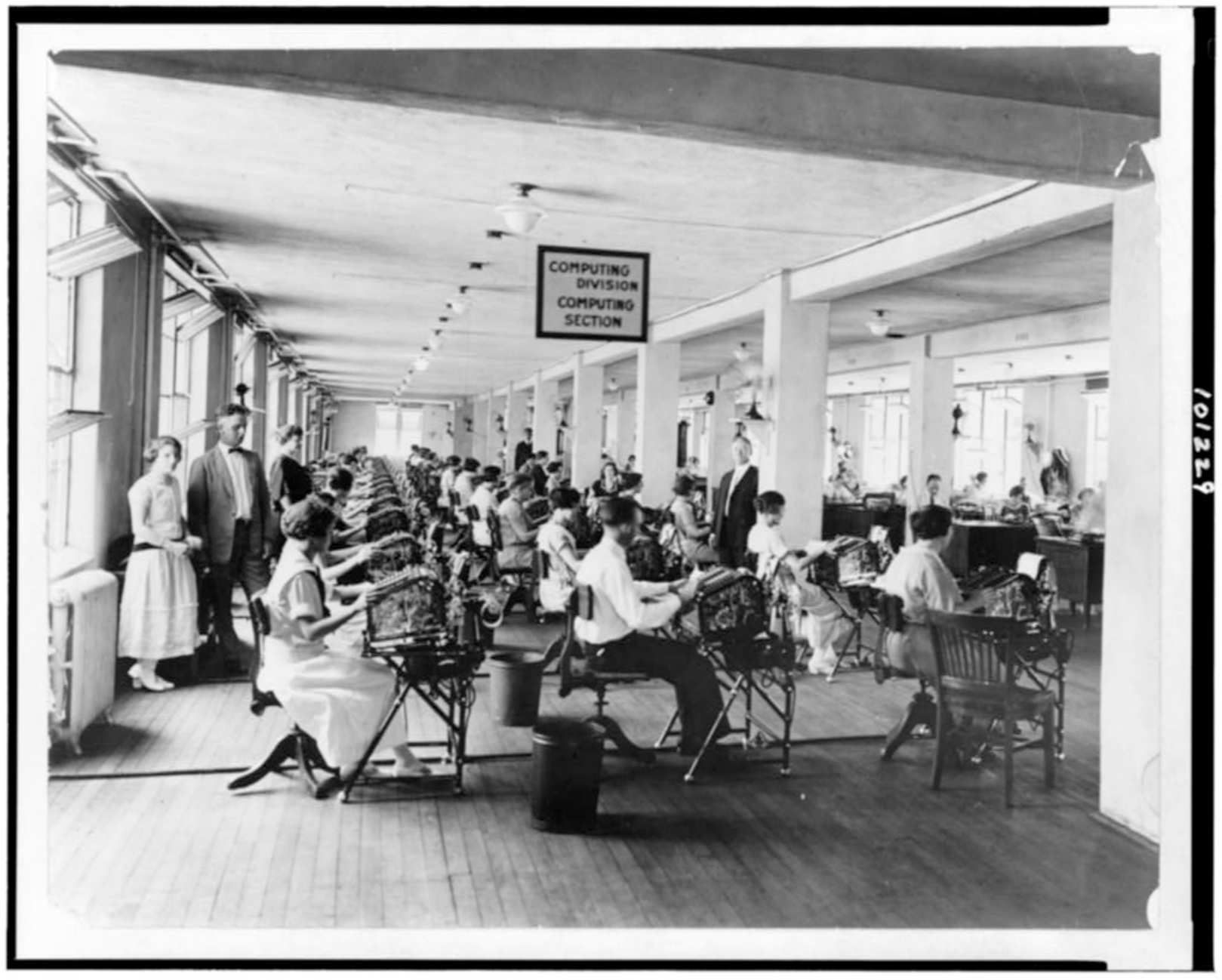

450

451 Figure 1A

452 


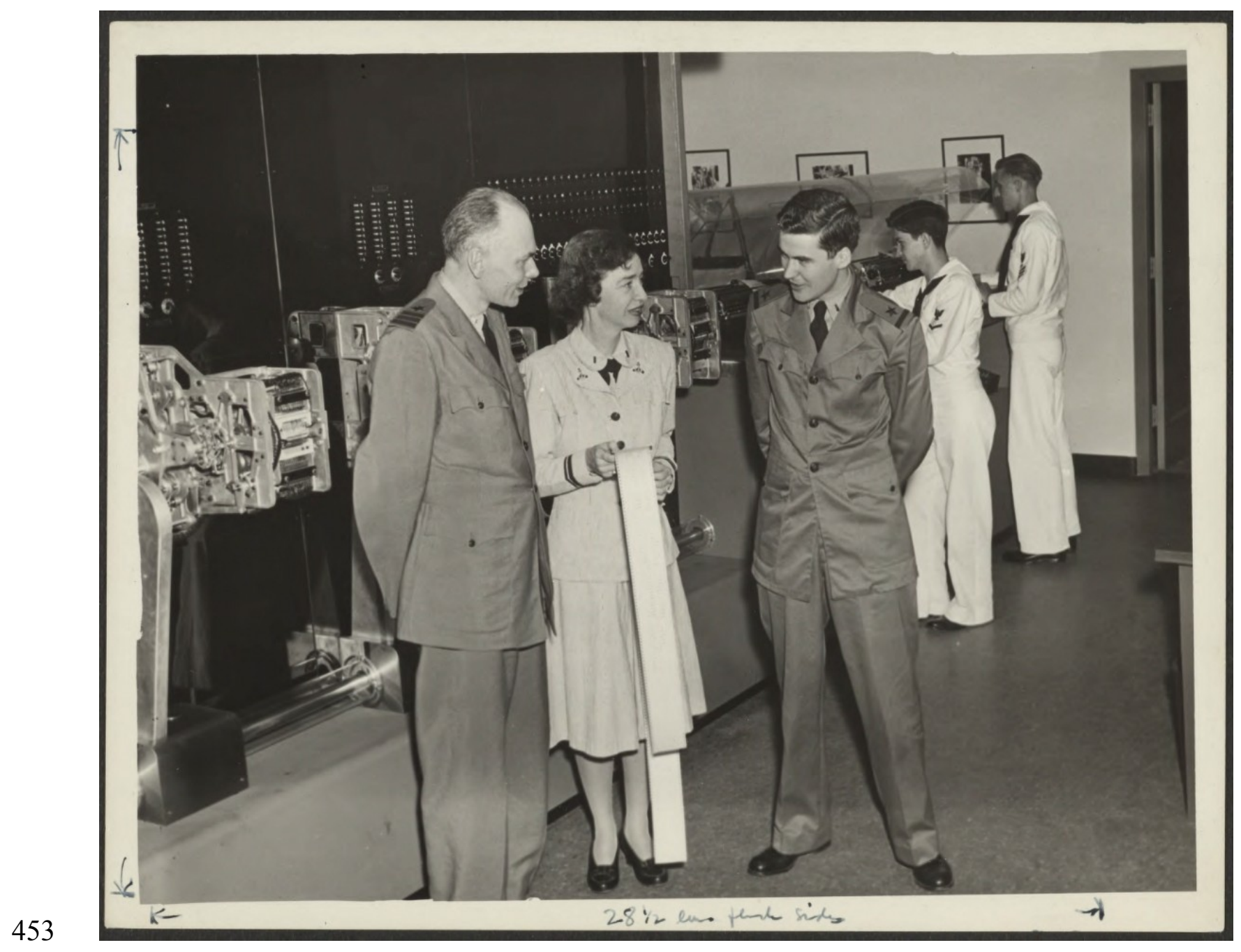

454 Figure 1B 


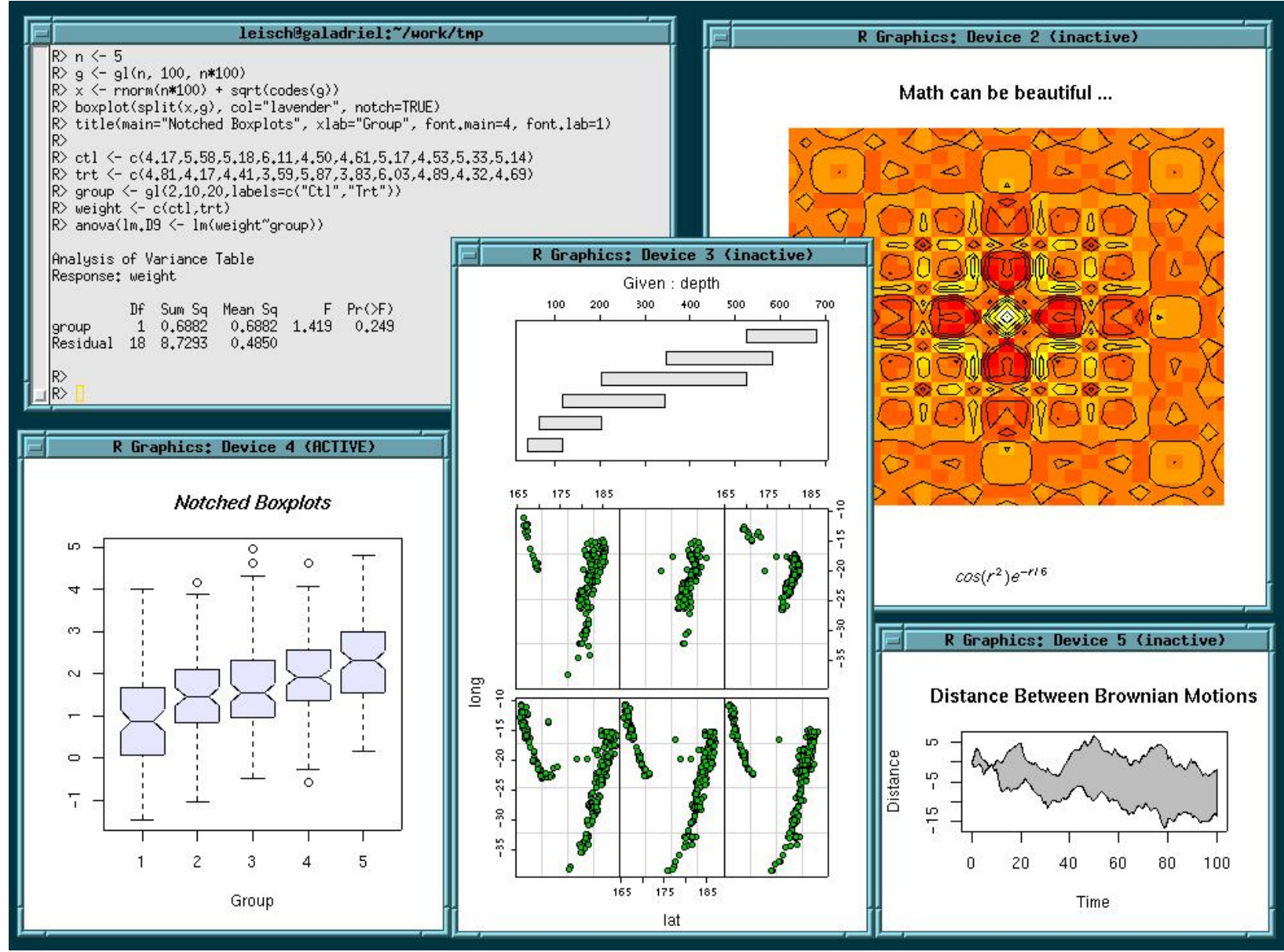



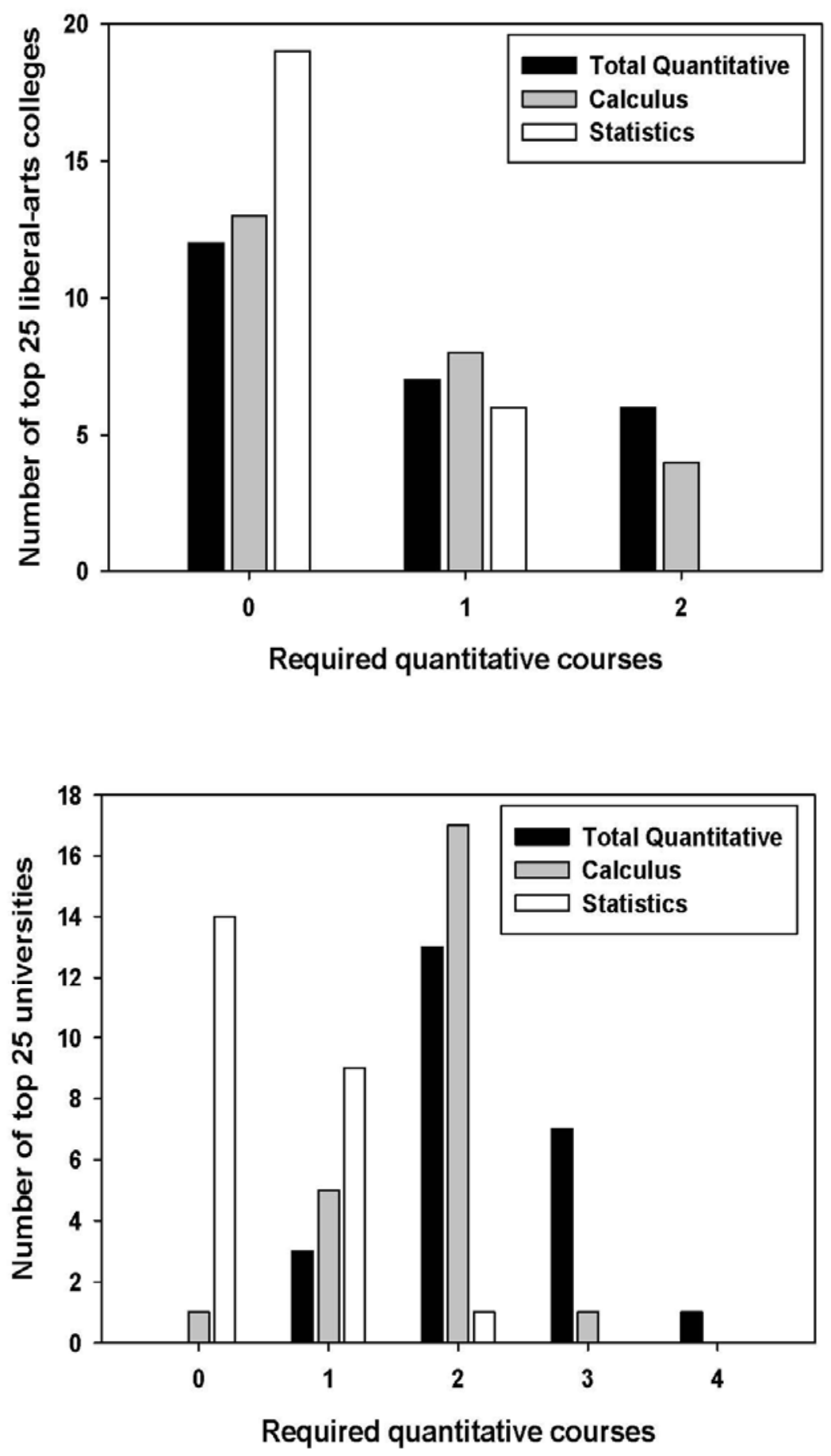

458

Fig. 2 


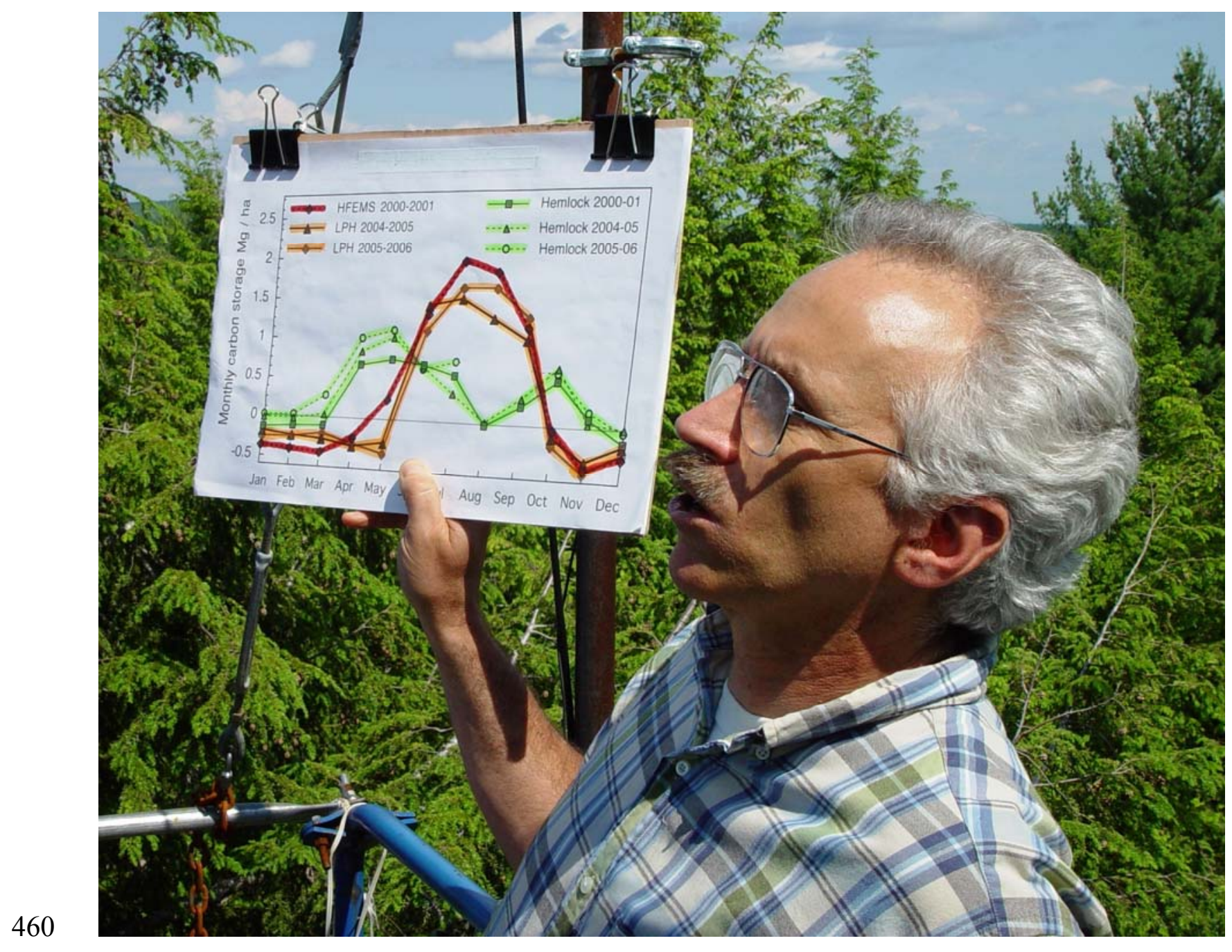

Figure 3. 
Box 1. Why " $P(10.2<\mu<29.8)=0.95$ " is not a correct interpretation of confidence interval, and what are confidence intervals, anyway?

29.8) or it is not. The probability that $\mu$ is in the interval is zero or one; we just do not know

which. A confidence interval actually asserts that $95 \%$ of the confidence intervals resulting from

hypothetical repeated samples (taken under the same random sampling protocol used for the

single sample) will contain $\mu$ in the long run. Think of a game of horseshoes in which you have

to throw the horseshoe over a curtain positioned so that you cannot see the stake. You throw a

horseshoe and it lands (thud!); the probability is zero or one that it is a ringer, but you do not

know which. The confidence interval arising from a single sample is the horseshoe on the

ground, and $\mu$ is the stake. If you had the throwing motion practiced so that the long run

proportion of successful ringers was 0.95 , then your horseshoe game process would have the

probabilistic properties claimed by $95 \%$ confidence intervals. You do not know the outcome

(whether or not $\mu$ is in the interval) on any given sample, but you have constructed the sampling

process so as to be assured that $95 \%$ of such samples in the long run would produce confidence a $95 \%$ confidence interval:

What this equation is telling us is that the true (but unknown) population mean $\mu$ will be found 
472 and U vary randomly from sample to sample. Once the sample is drawn, the lower and upper bounds of the interval are fixed (the horseshoe has landed), and $\mu$ (the stake) is either contained in the interval or it is not. confidence interval for $\mu$ when sampling from a Normal distribution is constructed based on the following probabilistic property:

$$
P\left(\bar{Y}-t_{\alpha / 2} \sqrt{S^{2} / n} \leq \mu \leq \bar{Y}+t_{\alpha / 2} \sqrt{S^{2} / n}\right)=(1-\alpha) .
$$

Here $t_{\alpha / 2}$ is the percentile of a t-distribution with $n-1$ degrees of freedom such that there is an area of $\alpha / 2$ under the t-distribution to the right of $t_{\alpha / 2}$, and $\bar{Y}$ and $S^{2}$ are respectively the sample mean and sample variance of the observations. The quantities $\bar{Y}$ and $S^{2}$ vary randomly from sample to sample, making the lower and upper bounds of the interval vary as well. The necessarily symmetric around the point estimates of those parameters. 


\section{Box 2. A prescription for statistical fluency.}

The problem of how to use calculus in the context of developing statistical fluency can be solved easily and well by rearranging courses and substituting different statistics courses (those hitherto rarely taken by ecologists) for many of the statistical methods courses now taken in college and graduate school. The suggested courses are standard ones, with standard textbooks, and already exist at most universities. Our prescription is as follows.

For undergraduate majors in the ecological sciences (including "integrative biology", ecology, evolutionary biology), along with students bound for scientific careers in resource management fields such as wildlife, fisheries, and forestry:

1. At least two semesters of standard calculus. "Standard" means real calculus, the courses taken by students in physical sciences and engineering. Those physics and engineering students go on to take a third (multivariable calculus) and a fourth semester (differential equations) of calculus, but these latter courses are not absolutely necessary for ecologists. Only a small amount of the material in those additional courses is used in subsequent statistics or ecology courses and can be introduced in those courses or acquired through self-study. Most population models must be solved numerically, methods for which can be covered in the population ecology courses themselves. (Please note we do not wish to discourage additional calculus for those students interested in excelling in ecological theory; our prescription, rather, should be regarded as minimum core for those who will ultimately have $\mathrm{Ph}$.Ds in the ecological sciences, broadly defined.) 
2. An introductory statistics course which lists calculus as a prerequisite. This course is standard everywhere; it is the course that engineering and physical science students take, usually as juniors. A typical textbook is Devore (2007).

3. A commitment to using calculus and post-calculus statistics in courses in life-science

For graduate students in ecology (sensu lato): curricula must go hand-in-hand with course requirements in calculus and post-calculus statistics. Courses in the physical sciences for physical science majors use the language of science - mathematics - and its derived tool - statistics - unapologetically, starting in beginning courses. Why don't ecologists or other life scientists do the same? The basic ecology course for majors should include calculus as a prerequisite and must use calculus so that students see its relevance.

1. A standard two-course sequence in probability and mathematical statistics. This sequence is usually offered for undergraduate seniors and can be taken for graduate credit. Typical extbooks are Rice (2006), Larson and Marx (2005), or Wackerly et al. (2007). The courses usually require two semesters of calculus as prerequisites.

2. Any additional graduate-level course(s) in statistical methods, according to interests and research needs. After a two-semester post-calculus probability and statistics sequence, the material covered in many statistical methods courses also is amenable to self-study.

3. Most ecologists will want to acquire some linear algebra somewhere along the line, because matrix formulations are used heavily in ecological and statistical theory alike. Linear algebra could be taken either in college or graduate school. Linear algebra is often reviewed extensively in courses such as multivariate statistical methods and population 
ecology, and necessary additional material can be acquired through self-study. Those ecologists whose research is centered on quantitative topics should consider formal coursework in linear algebra.

The benefit of following this prescription is a rapid attainment of statistical fluency.

Whether students in ecology are focused more on theoretical ecology or on field methods, conservation biology, or the interface between ecology and the social sciences, a firm grounding in quantitative skills will make for better teachers, better researchers, and better interdisciplinary communicators (for good examples see Armsworth et al. 2009 and other papers in the associated special feature on "Integrating ecology and the social sciences" in the April 2009 issue of the Journal of Applied Ecology). Since our prescription replaces courses rather than adds new ones, the primary cost to swallowing this pill is either to recall and use calculus taken long ago or to take a calculus refresher course. 